\title{
Comparing the Effect of Using Monolingual versus Bilingual Dictionary on Iranian Intermediate EFL Learners' Vocabulary Learning
}

\author{
Saeideh Ahangari ${ }^{1} \&$ Shokoufeh Abbasi Dogolsara ${ }^{2}$ \\ ${ }^{1}$ Department of English, Tabriz Branch, Islamic Azad University, Tabriz, Iran \\ ${ }^{2}$ Department of English, Roudsar and Amlash Branch, Islamic Azad University, Roudsar, Iran \\ Correspondence: Saeideh Ahangari, Department of English, Tabriz Branch, Islamic Azad University, Tabriz, \\ Iran. E-mail: S_ahangari@yahoo.com
}

$\begin{array}{ll}\text { Received: March 3, } 2015 & \text { Accepted: April 14, } 2015 \quad \text { Online Published: May 28, } 2015 \\ \text { doi:10.5539/elt.v8n6p141 } & \text { URL: http://dx.doi.org/10.5539/elt.v8n6p141 }\end{array}$

\begin{abstract}
This study aimed to investigate the effect of using two types of dictionaries (monolingual and bilingual) on Iranian intermediate EFL learners' vocabulary learning. An OPT (Oxford placement test, 2001) was administered among 90 students 60 of whom were selected as the participants of this study. They were sophomore students studying English as a foreign language, with the age range of 19-27. They were then divided into two comparison groups: Monolingual Dictionary (MD) and Bilingual Dictionary (BD) groups. A pretest of vocabulary was administered to both groups. Then both groups were given a five-session treatment. One group was taught vocabulary based on monolingual dictionary, and the other group was taught vocabulary through bilingual dictionary. After the treatment, the same version of vocabulary test was given to both groups as posttest to check the effectiveness of the treatments. The results of Paired-Samples and Independent Samples t-tests revealed that the effect of monolingual dictionary on learners' vocabulary learning was more than that of the bilingual dictionary use. The implications and recommendations will also be presented.
\end{abstract}

Keywords: bilingual dictionary, EFL learners, monolingual dictionary, OPT

\section{Introduction}

Dictionary plays an important role in learning vocabulary. There is little doubt that dictionary is one of the indispensible instruments for vocabulary learning (Zarei \& Lotfi, 2013). In EFL situations, language learners make use of different kinds of dictionaries for a variety of purposes, both at work and in education. The big variety of bilingual and also the monolingual English dictionaries, their availability and EFL learners' accessibility to them have led to a controversy as to what kind of dictionary to use, and this tendency has long been at the core of vocabulary teaching and learning activities. Eeds and Cockrum (1985) highlighted the important role of dictionary and its use as the conventional method of instruction in both first and second language learning. Dictionaries, as the conventional method of instruction, provide information about the language, usually not found elsewhere. They supply useful information concerning grammatical points, usage, formality or informality, synonym, use of derivative affixes, and discrimination between spoken and written English which are not generally dealt with in textbooks. Holi Ali $(2012$, p. 1) pointed out, "Dictionaries are as indispensible tools for mastering vocabulary and learning a foreign language in general. It provides learners with access to a vast amount of information about words and their usage. Using dictionaries can be seen as an explicit strategy for learning a foreign language vocabulary or as communication strategy".

Thornbury (2002) emphasized the importance of instruction in dictionary use in that it is regarded as a way of promoting learners' autonomy, and provides a possibility to continue word acquisition outside the formal study of the language. In addition, it helps learners understand texts containing specialized vocabulary that is not usually taught in class.

Despite the importance of dictionaries for EFL learners, little research has been conducted in Iran related to the role of dictionary in vocabulary learning. There has been a paucity of research on the effects of monolingual versus bilingual dictionary on EFL learners' vocabulary learning. The main purpose and primary focus of the present study was to investigate the effect of two types of dictionary (monolingual versus bilingual) on Iranian EFL learners' vocabulary learning as they encounter various contexts. These two variables and their potential 
interaction and effect on each other have not been investigated thoroughly in the Iranian context yet. So the present study was going to fill this gap and shed more light on this controversial issue by finding any possible effect of using bilingual vs. monolingual dictionaries on Iranian intermediate EFL learners' vocabulary learning. Therefore, the following null hypotheses were formulated in this study:

H01: Monolingual dictionaries do not affect Iranian intermediate EFL Learners' vocabulary learning.

H02: Bilingual dictionaries do not affect Iranian intermediate EFL Learners' vocabulary learning.

H03: There is no significant difference in the vocabulary learning of Monolingual dictionary group and Bilingual dictionary group.

\section{Review of the Literature}

\subsection{The Importance of Dictionary Use}

As Holi Ali (2012, p. 3) showed, "Dictionary is an important educational tool that plays a vital role in various processes of language learning including reading comprehension and vocabulary learning and acquisition". In EFL learning situations, as language learners come across an unknown word, one of the possible strategies they think of and resort to is consulting a dictionary. The matter of what sort of dictionaries to use in the foreign language classroom has always been an on-going controversial issue. Some researchers such as Neubach and Cohen (1988) are of the view that consulting a dictionary appears to enhance vocabulary learning, and to maximize retention of words as well. Furthermore, Hulstijn, Hollander, and Greidanus (1996), Luppescu and Day (1993) concluded that consulting a dictionary is helpful for L2 acquisition and facilitates both vocabulary acquisition and comprehension of texts.

The results of Bogaards' study (1998) showed that learners are able to identify and extract the correct definition and meaning of unfamiliar and unknown words in the dictionary more easily than they can exactly guess the meaning of the words from context. A number of studies have shown that L2 learners' use of dictionary improves reading comprehension and leads to lexical development. Researchers such as Summers (1988), Luppescu and Day (1993) concluded that the L2 English learners who made use of a dictionary had significantly better scores on both comprehension and vocabulary tests. In another study, Knight (1994) reported a study which was conducted by involving Spanish learners who had access to a dictionary scored higher on comprehension and vocabulary tests.

With regard to the use of dictionary in second language and concerning other perspectives of dictionary utilization in terms of advantages, Nation (2008) noted that dictionary can be helpful to the learners in three major fields. He maintains that, by consulting dictionary, learners understand words that they meet in reading and listening, find words that they need for speaking and writing, and remember words. In line with these studies, Garcia's (2012) study was supportive of the point that dictionary is an effective tool for solving lexical problems in writing and that the subjects use sophisticated look-up strategies, regardless of their proficiency level. The findings of some previous studies by Prichard (2008), Summers (1988), and Li and Lou (2012) showed that EFL learners' use of dictionary, while dealing with texts and unknown words, leads to their improved comprehension and vocabulary development.

Wang (2007) referred to dictionary as a powerful analytic tool in organizing language, providing differentiation from other similar words, which are deemed as necessary for accurate comprehension, and helping fix new vocabulary in the memory by having learners focus their attention to opposite words or words having close meanings.

Dictionaries can vary depending on the various purposes for which they may be used. As evidence of this point, Nation (2001) identified three distinguishing purposes for dictionary use, involving comprehension (decoding), production (encoding), and learning. As to effectiveness of dictionaries in vocabulary learning, Hulstijin, Hollander and Greidanus (1996), asserted that if learners use and consult a dictionary whenever they come across unknown words, their scores will be higher and more notable than those who do not make use of it. Luppescu and Day (1993) conducted a study and reported that dictionary is found to have a significant effect on learners' ability in word-to-word vocabulary definition test.

\subsection{Bilingual and Monolingual Dictionaries Preferences and Vocabulary Learning}

Brown and Payne (1994, cited in Fan, 2003, p. 223) recognized and highlighted five procedures in the process of L2 vocabulary learning and development: Providing learners with sources for encountering new words, obtaining a clear picture and image or the words learners are exposed to (through visual or auditory forms or a combination of both), learning the meaning of the words, establishing a strong memory connection between the 
forms and the meanings of the words, and consequently, using the words and applying them in similar contexts.

There has been a controversy regarding the use of monolingual or bilingual dictionaries. Some researchers advocated the use of monolingual dictionaries while others have been doubtful about the use of monolingual dictionaries and proposed the use of bilinguals instead. Hayati and Akram (2006) for example, reported that many highly frequently used words are dealt with more appropriately in monolingual dictionaries than other dictionaries because these words have got wider frequency of use in English textbooks. They, furthermore, showed that a monolingual dictionary demonstrates not only definitions but also other important aspects of vocabulary. He prefers the use of monolingual dictionary because it raises learners' fluency by offering definitions of new words and expressions in context. The bilingual dictionaries, in contrast, demand word-for-word translation and equivalents that may not be as appropriate equivalents in some situations and might cause confusion and ambiguity. Bejoint (1981) proposed that those learners who use monolingual dictionaries will get into thinking in the target language.

Yorio (1971) and Bensoussan et al. (1984) however, pointed out that the bilingual dictionaries give students security of concrete answers, whereas monolingual dictionaries often get students to guess and predict the meaning, which sometimes culminates in doubt and confusion. Monolingual dictionaries may provide learners with give long, complicated, and confusing description that might not express the intended and desired meaning.

Knight (1994) and Schmitt (2000) had a narrow and different view on the priority in the application of dictionaries. They suggested that students had better infer word meaning through applying contextual cues and incidental learning of vocabulary by means of extensive reading or listening, instead of studying their short definitions or translations found in the dictionaries. They maintained that learners' frequent consultation of dictionaries leads to short-term memory and hinders comprehension processes.

\subsection{Empirical Studies on Dictionary Types and Vocabulary Learning}

Holi Ali (2012) conducted a study on using monolingual dictionary in EFL context. This study focused on exploring teachers' and students' attitudes about the use of the dictionary and its training. The results indicated that the vast majority of the teachers preferred their students to use monolingual dictionaries because they will help them acquire foreign language more effectively and that the bilingual dictionaries are likely to encourage translation, whereas most of the students would prefer to use bilingual and bilingualized dictionaries because they feel they are practical and easy to use.

Zarei and Naseri (2008) examined the effect of three kinds of dictionaries (monolingual, bilingual, and bilingualized) on advanced learners' vocabulary comprehension and production. The results of his study revealed that different types of dictionaries were found appropriate for learners at different levels of proficiency.

Amiriyan and Heshmatifar (2013) investigated the impact of using electronic dictionary on vocabulary learning and retention of Iranian EFL learners, through which they concluded that the electronic dictionary had better effect on learning and long-term retention of vocabulary of Iranian lower-intermediate EFL learners.

Ganji Khoosf (2014) aimed to investigate the effectiveness of different dictionary tasks in EFL learners' autonomy and vocabulary learning among Iranian Guidance and High school students. The findings of the study revealed a significant relationship between using dictionary tasks and improving EFL learners' autonomy and permanent vocabulary learning.

Flyn's (2007) area of study was an aim to examine the effects of electronic dictionaries, printed dictionaries and no dictionaries on vocabulary knowledge and reading comprehension with Japanese EFL university students. The results showed that dictionary usage resulted in higher scores and performance on the comprehension and vocabulary knowledge than the students who read without dictionaries. Electronic dictionary usage resulted in superior gains on the comprehension and vocabulary than printed dictionary usage.

Hayati and Fattahzadeh (2006) aimed at investigating the effect of monolingual and bilingual dictionaries on vocabulary recall and retention of EFL learners. By conducting this study, they reported that the students who used a bilingual and monolingual dictionary learned nearly the same numbers of words. Dictionary- types had no significant effect on learners' vocabulary recall and retention. It, however, was revealed that speed had a direct relation with bilingual dictionaries.

Sardari and Rahimi (2014) study was to determine the effect of contextual clues, mainly given through the use of Oxford dictionary examples and definitions, on the knowledge of lexis in Iranian pre-intermediate EFL learners. The results of this study confirmed that there was no significant difference between the performance of the experimental and that of the control group. 
Zarei and Lotfi's study (2013) targeted at examining the effect of different types of dictionaries on the recall and recognition of concrete and abstract L2 vocabulary conducted at the Iranian EFL high school students. They examined two types of dictionaries (monolingual and bilingual dictionaries) to find out how well they could affect learners' abstract and concrete L2 vocabulary in EFL contexts. The findings of this study revealed two points: First, bilingual dictionary had better effect than the monolingual dictionary in the vocabulary recognition, and word type did not have any effect on the comprehension of the new words. Second dictionary type and word type were not effective in vocabulary production.

\section{Methodology}

\subsection{Participants}

The participants in this study were sixty Iranian EFL students who were studying English at intermediate level at the Islamic Azad University, Roudsar and Amlash branch, Iran. They were sophomore students with the age range of 19-27. To ensure the homogeneity of the participants, an OPT test (Oxford Placement Test, 2001) was administered. The OPT test was given to ninety students out of whom sixty were selected based on the results of the test. That is, the students whose scores fell between one standard deviation below and above the mean were considered as participants of the study. Then, they were randomly assigned into the Bilingual Dictionary (BD) and Monolingual Dictionary (MD) groups.

\subsection{Instruments and Materials}

The instruments and materials used in the current study were as follows:

a) The OPT test: The OPT test (Oxford Placement Test, 2001) for intermediate level, which was administered to determine the participants' proficiency and homogeneity, consisted of multiple-choice items.

b) Vocabulary pretest and posttest: The pretest included a vocabulary test consisting of 20 multiple-choice items (recognition type). The vocabulary test was determined and constructed based on the original vocabulary book entitled "504 Absolutely Essential Words, Fifth Edition" (Bromberg, Lieb, \& Traiger, 2013). It is a course-book on morphology that the students in the university cover during their laboratory course of study. The same version of vocabulary multiple-choice-item test, with rearrangement of some items, was administered as posttest to the both groups.

c) The material for the treatment: The material selected in the treatment for both groups included one hundred words extracted from the same native vocabulary book (504 Absolutely Essential Words, Fifth Edition ), based on which the pretest and posttest were constructed. The lexical items, selected for the sake of treatment, were divided into five sections, each of which included 20 words.

\subsection{Procedure}

After the administration of the OPT test and pretest in both groups, they underwent their treatments (monolingual dictionary use in one group and bilingual dictionary use in the other group) for the same period of time through the same material and based on the same methodology. The material selected for this purpose included one hundred words taken from a native vocabulary book entitled "504 Absolutely Essential Words, Fifth Edition" (Bromberg, Lieb, \& Traiger, 2013). The words selected for the purpose of the treatment were sorted into five sections, each of which consisted of 20 words. Totally, five sessions of treatment was offered to the both groups, and each section of the words was taught in one session. The participants of the two groups were supposed to work on the material through the instructions provided to them.

The MD group was taught in five sessions within two subsequent weeks, including three sessions in one week and two sessions in the other week. Based on the schedule for this group, each session was completed by introducing exactly twenty words which were taught to the participants of the group through a variety of exercises. The participants of this group were just required to use a monolingual English dictionary during each session. They were supposed to work on the English words and learn the meaning of them through their definitions in English, antonyms, opposites, and exemplifications. They received their classmates' views and feedback as they practiced the new words in the treatment session. They were greatly encouraged to extract and find the meaning of the newly introduced words by referring to their definition in L2 or by resorting to their synonyms in Oxford Advanced Learners' Dictionary. The application of the participants' native language equivalents for the meaning of the words was strongly avoided. Each session was terminated by providing a sample vocabulary exercise by which the participants were supposed to do the vocabulary exercise in the form of fill-in-blank.

The BD group was taught the same material but through a bilingual dictionary in exactly the same period of 
time like the MD group. To meet the requirements of this group, the participants of this group were allowed to use a bilingual dictionary (an English- Persian dictionary) to extract, practice and learn the meaning of the new words and expressions they were introduced during each session. Likewise, they were asked to find Farsi equivalents from the bilingual dictionary for the words they study. Like the other group, the participants of this group were given a sample vocabulary exercise to work on at the end of each treatment session. After the completion of treatment period for the both groups within five sessions, they were given the post-test, which was the same version of test on vocabulary administered as pretest, with a rearrangement of some items in the posttest.

\subsection{Design}

The study employed pretest-posttest comparison group design as one of the quasi-experimental designs. The independent variables of the study were monolingual and bilingual dictionaries and the dependent variable was vocabulary learning

\subsection{Data Analysis}

The collected data were entered into the SPSS 16.0 for further analysis. Two Paired- Samples t-tests and an Independent-Samples t-test were used to test the null hypotheses of the study and the alpha level for significance testing was set at .05 .

\subsection{Results}

This section is devoted to the description of the statistical analyses concerning the test and the null hypotheses proposed for the purpose of this research. The findings of the study are represented as follows:

\subsubsection{First Null Hypothesis}

The first null hypothesis of the study suggested that Monolingual dictionaries do not affect Iranian intermediate EFL Learners' vocabulary learning. For this purpose, a Paired-Samples t-test was conducted for the comparison of the first group's prêt-test and post-test mean scores. The descriptive statistics are represented in Table 1.

Table 1. Descriptive statistics of the paired-samples t-test for the MD group

\begin{tabular}{|c|c|c|c|c|c|}
\hline & & Mean & $\mathrm{N}$ & Std. Deviation & Std. Error Mean \\
\hline \multirow{2}{*}{ Pair 1} & PreEX & 12.06 & 30 & 3.99 & .72 \\
\hline & PosEX & 15.23 & 30 & 2.66 & .48 \\
\hline
\end{tabular}

Table 1 shows that the posttest means score (15.23) of the MD group was more than their pretest mean score (12.06). The standard deviation for the posttest was less than the pretest. This may give an image of less variability among MD group's posttest scores compared to their pretest scores. In order to find out whether there was a significant difference between the pretest and posttest mean scores of the MD group, the results of Paired-Samples t-test are presented in Table 2.

Table 2. Paired samples t-test for (MD group)

\begin{tabular}{llllllll}
\hline & & \multicolumn{2}{l}{ Paired Differences } & \multirow{2}{*}{$\mathrm{t}$} & & \multirow{2}{*}{ df } & Sig. (2-tailed) \\
\cline { 2 - 5 } & & Mean & Std. Deviation & Std. Error Mean & & & \\
\hline Pair 1 & PreEX-PosEX & 3.16 & 1.51 & .27 & 11.48 & 29 & .000 \\
\hline
\end{tabular}

As illustrated in Table 4, there is a significant difference, $t(29)=11.48, p=.000$, between the pretest-posttest mean scores of the MD group. Therefore, the first null hypothesis of the study is rejected.

\subsubsection{Second Null Hypothesis}

The second hypothesis of the study proposed that Bilingual dictionaries do not affect Iranian intermediate EFL Learners' vocabulary learning. To investigate this hypothesis, a Paired-Samples t-test was run for the BD group. 
Table 3. Descriptive statistics of paired-samples t-test for the BD group

\begin{tabular}{|c|c|c|c|c|c|}
\hline & & Mean & $\mathrm{N}$ & Std. Deviation & Std. Error Mean \\
\hline \multirow{2}{*}{ Pair 1} & PreCON & 12.13 & 30 & 3.98 & .72 \\
\hline & PosCON & 13.16 & 30 & 2.79 & .50 \\
\hline
\end{tabular}

As the results show, the mean score of BD Group in pretest was 12.13 but in the posttest was 13.16 . So the participants' vocabulary gain after treatment was notable and really something to be taken into account. This clue is considered an indicator of the rejection of the second null hypothesis. Furthermore, standard deviation (Std. Deviation) for the posttest in this group was less than that of the pretest. This may be indicative of less variability among BD group's posttest scores than that of the pretest. Likewise, the next table (Table 4) provides further clue regarding the rejection of the second null hypothesis.

Table 4. Paired-samples t-test for the BD group

\begin{tabular}{llllllll}
\hline & & \multicolumn{2}{l}{ Paired Differences } & \multirow{2}{*}{ T } & df & Sig. (2-tailed) \\
\cline { 2 - 5 } & & Mean & Std. Deviation & Std. Error Mean & & & \\
\hline Pair 1 & PreCON-PosCON & 1.03 & 1.60 & .29 & 3.52 & 29 & .001 \\
\hline
\end{tabular}

As shown in Table 4, there is a significant difference, $t(29)=3.52, p=.001)$, between the pretest-posttest mean scores of the BD Group. Therefore, the second null hypothesis of the study, which proposed that bilingual dictionaries do not affect Iranian intermediate EFL learners' vocabulary learning, is rejected. As a result, the second hypothesis is rejected.

\subsubsection{Third Null Hypothesis}

The third null hypothesis of this study was constructed on the supposition that there is no significant difference in the vocabulary learning of Monolingual dictionary group and Bilingual dictionary group. To examine this hypothesis, an Independent-Samples t-test was conducted. The descriptive statistics of the results are represented in Table 5.

Table 5. Descriptive statistics for the BD and MD groups in the posttest

\begin{tabular}{llllll}
\hline & DT & N & Mean & Std. Deviation & Std. Error Mean \\
\hline \multirow{2}{*}{ Vocabulary } & Monolingual & 30 & 15.23 & 2.66 & .48 \\
& Bilingual & 30 & 13.16 & 2.79 & .50 \\
\hline
\end{tabular}

According to Table 5, the mean of the MD group in the posttest was 15.23, and that of the BD group was 13.16. The results showed that the MD group outperformed the BD Group. Therefore, it is concluded that the using monolingual dictionary as an independent variable in this study was more effective than that of bilingual dictionary as the second independent variable. Furthermore, the standard deviation value for the MD group, according to the table, is less than the other group, meaning that there was less variability in the scores of the MD's participants compared with those of the BD group's participants. However, in order to find out whether there was a significant difference between the two groups' mean scores in the posttest, the results of the Independent-Samples t-test are presented in Table 6. 
Table 6. Independent-Samples t-test for the MD and BD Groups in the Posttest

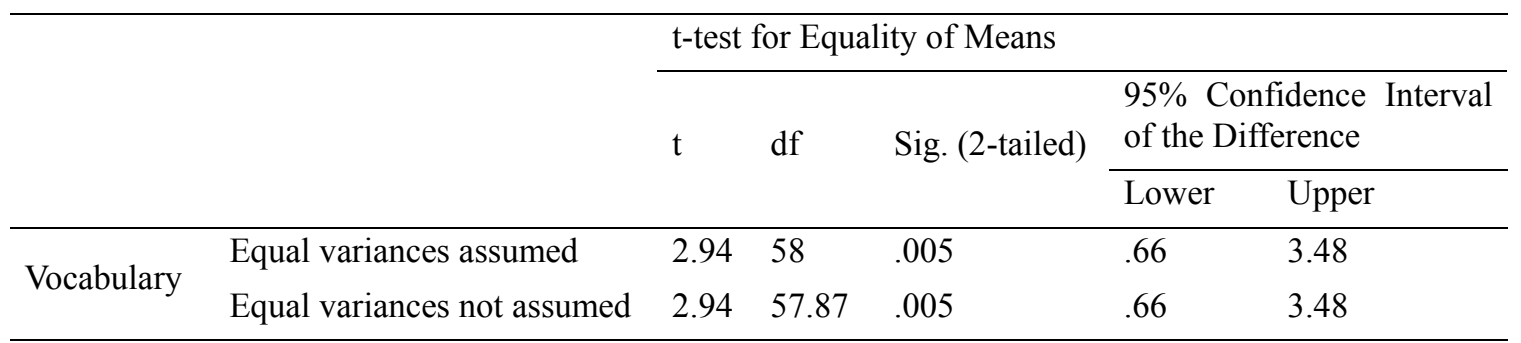

As Table 6 demonstrates, there is a significant difference, $\mathrm{t}(58)=2.94, \mathrm{p}=.005$, between the BD and MD groups. Therefore, the third null hypothesis of the study was rejected.

\section{Discussion}

The objective of this study was to investigate the effect of using monolingual and bilingual dictionaries as two common educational instruments in EFL contexts on Iranian intermediate EFL learners' vocabulary learning. The results of this study showed that the monolingual and bilingual dictionaries were effective in vocabulary learning, but the monolingual dictionary use had a significant effect on Iranian intermediate EFL learners' vocabulary learning compared to the bilingual dictionary use. It was revealed that learners' vocabulary learning task could be facilitated as a result of their integration into monolingual dictionary practice which fostered their communication activity while exchanging their views on words.

The findings of this study appear to be in line with Zarei and Naseri's (2008) work whose main objective was to investigate the comparative effects of three kinds of dictionaries (monolingual, bilingual, and bilingualized) on advanced learners' vocabulary comprehension and production. The results of his study revealed that different types of dictionaries were appropriate for learners who were at different levels of proficiency.

These findings seem to be, to some extent, in line with the research study carried out by Amiriyan and Heshmatifar (2013) whose effort was to test the impact of making use of electronic dictionary on Iranian EFL learners' vocabulary learning and retention. By conducting this research, they reported the significant effect of electronic dictionary on EFL learners' vocabulary input, and concluded that the electronic dictionary had better effect on learning and long-term retention of vocabulary of Iranian lower-intermediate EFL learners.

The findings of this study also, to some extent, accord with Flyn's (2007) research work, through which he examined the effects of electronic dictionaries, printed dictionaries and no dictionaries on Japanese EFL university students' vocabulary knowledge and reading comprehension as an EFL study. The results showed that the EFL learners who used printed and electronic dictionaries represented better performance in comprehension and vocabulary learning than those who did not use any dictionary. In other words, according to his research report, dictionary usage resulted in higher scores and performance on the comprehension and vocabulary knowledge than the students who read without dictionaries. This study, furthermore, indicated that individuals' use of electronic dictionary brought about higher gains on the comprehension and vocabulary than printed dictionary usage

From the findings of his study, it was revealed that using and encouraging learners to make use of monolingual dictionary can be important, and play role in learners' tendency to make use of monolingual dictionary both as a communication practice and a motivation to be integrated into the real and native contexts into which words are given. Jiang (2000) stressed that contextual cues can affect the process and outcome of word inference. A context should provide sufficient clues which help the EFL learners to find out the meaning of unknown words. A shortage in the knowledge of lexis is observed among Iranian EFL learners. Kafipour (2009) stated that many EFL learners have a limited repertoire of vocabulary affecting their comprehension when they are producing the language.

Therefore, the findings of this study, being in line with those of some other studies mentioned above, can provide a good justification for placing more emphasis on using monolingual dictionary more frequently than bilingual dictionaries in EFL classes. According to the findings of this study, using monolingual type of dictionary, as the conventional tool of instruction in both first and second language learning, can be more effective than a bilingual dictionary in learning vocabulary in EFL classes.

\section{Conclusion}

The findings demonstrated that monolingual dictionary usage was more effective than bilingual dictionary 
application, as an educational instrument, in Iranian EFL classes. Monolingual dictionary requires more effort from its users and the increased processing of words, as a result of integration into monolingual dictionary, leads to improved learning of vocabulary. Learners' better performance in vocabulary learning and production of abstract and concrete words can be partially attributed to the fact that monolingual dictionaries supply sufficient contexts in their definitions and, in particular, in their exemplification of new words and expressions which assist learners to learn new words and vocabulary items, and to produce them in similar contexts. Therefore, a monolingual dictionary considers the importance of using contextual clues in representing lexical items. Providing second/ foreign learners with a de-contextualized list of words is just something requiring memorizing vocabulary items with making no practical word map in learners' mind. Supplying contextualized vocabulary, in turn, can create permanent and long retention of information about a word in learner's mind. In this regard, authentic dictionaries are viewed as effective and useful materials for teaching and learning vocabulary.

The findings of the present study will be helpful to English teachers and test designers in EFL classes. Teachers are supposed to assist EFL learners to maximize their knowledge of lexical competence by encouraging them to use monolingual kinds of dictionaries, the example of which is Oxford dictionary. The advantage of this kind of monolingual dictionary is that it is rich in contextual clues which help create a meaningful vocabulary learning strategy for intermediate learners by teaching different usages of different meanings of the same word. This manner of contextualized vocabulary learning facilitates learning and seeks to involve students/learners actively within the process of learning/acquiring vocabulary. The widely used approach for constructing and testing vocabulary in EFL contexts is multiple-choice-item type of exercise. This study suggests that test constructors involve learners in some exercises requiring them to infer and extract the meaning of words in the contexts into which they are given. It will be useful for test constructors to find out how well learners are able to seek for and understand other contextually appropriate vocabulary.

This study was targeted and conducted at Iranian intermediate EFL learners. It is suggested that the future studies of similar nature employ other proficiency levels of the EFL learners such as high school level or upper-intermediate learners. In this study, only printed monolingual and bilingual dictionaries were tested on EFL learners' vocabulary learning. The future experiments can address the effectiveness of electronic monolingual and bilingual types of dictionaries.

\section{References}

Bensoussan, M., Sim, D., \& Weiss, R. (1984). The effect of dictionary usage on EFL test performance compared with student and teacher attitudes and expectations. Reading in a Foreign Language, 2, 262-276.

Bogaards, P. (1998). Using dictionaries: Which words are looked up by foreign language learners? In B. T. S. Atkins, \& K. Varantola (Eds.), Studies of dictionary use by language learners and translators (pp. 151-157). Tubingen, Germany: Niemeyer.

Bromberg, M., Liebb, J., \& Traiger, A. (2013). 504 Absolutely essential words (5th ed.). Tehran: Zaban Mehr.

Brown, C., \& Payne, M. E. (1994). Five essential steps of processes in vocabulary Learning. Paper presented at the TESOL Convention, Baltimore, Md.

Fan, Y. M. (2003). Frequency of use, perceived usefulness, and actual usefulness of second language vocabulary strategies: A study of Hong Kong learners. The Modern Language Journal, 87(2), 222-241.

Flyn, M. H. (2007). Electronic dictionaries, printed dictionaries and no dictionaries: the effects on vocabulary knowledge and reading comprehension (Unpublished Master thesis). University of Birmingham.

Ganji Khoosf, S. (2014). Improving EFL learners' vocabulary learning via dictionary tasks. FLTJ, 2(1), 16-21.

Garcia, S. S. (2012). Dictionary use in L1 writing (PhD dissertation). University of Essex, UK.

Hayati, \& Fattahzadeh. (2006). The effect of monolingual and bilingual dictionaries on vocabulary recall and retention of EFL learners. The Reading Matrix, 6(2), 125-133.

Hodi Ali, H. I. (2012). Monolingual Dictionary Use in an EFL Context. English Language Teaching, 5(7), 2-7.

Hulstijn, J., Hollander, M., \& Greidanus, T. (1996). Incidental vocabulary learning by advanced foreign language students: The influence of marginal glosses, dictionary use, and reoccurrence of unknown words. The Modern Language Journal, 80, 327-339.

Jiang, N. (2000). Lexical representation and development in a second language. Applied Linguistics, 21(1), 47-77.

Kafipour, R. (2009). Vocabulary learning strategies of Iranian undergraduate EFL students and its relation to 
their vocabulary size. European Journal of Social Sciences, 11(1), 39-50.

Knight, S. (1994). Dictionary use while reading: The effects on comprehension and vocabulary acquisition for students of different verbal abilities. The Modern Language Journal, 78(3), 285-299. http://dx.doi.org/10.1111/j.1540-4781.1994.tb02043.x

Li, L., \& Lou, X. (2012). A survey on English majors' dynamic trends of dictionaries using. Open Journal of Modern Linguistics, 2(2), 79-83.

Luppescu, S., \& Day, R. (1993). Reading, dictionaries, and vocabulary learning. Language Learning, 43(2), 263-287. http://dx.doi.org/10.1111/j.1467-1770.1992.tb00717.x

Nation, I. S. P. (2008). Teaching vocabulary (strategies and techniques). Boston: Heinie.

Neubach, A., \& Cohen, A. D. (1988). Processing strategies and problems encountered in the use of dictionaries. Dictionaries: Journal of the Dictionary Society of North America, 10, 1-19. http://dx.doi.org/10.1353/dic.1988.0018.

Prichard, C. (2008). Evaluating L2 readers' vocabulary strategies and dictionary use. Reading in a Foreign Language, 20(2), 216-231.

Prichard, C. et al. (2008). Defining and measuring selective dictionary use among L2 readers. JALT Proceedings, 926-935. Tokyo.

Sardari, S., \& Rahimi, R. (2014). THE effect of using Oxford dictionary contextual clues on Iranian EFL learners' knowledge of lexis. Asian Journal of Management Sciences and Education, 2(4), 117-127.

Schmitt, N. (2000). Vocabulary in language teaching. Cambridge: Cambridge University Press.

Summers, D. (1988). The role of dictionaries in language learning. In R. Carter, \& M. McCarthy (Eds.), Vocabulary and language teaching (pp. 111-125). London: Longman.

Thornbury, S. (2008). How to teach vocabulary. England: Pearson Education Limited.

Wang, M. H. (2007). The effects of dictionary skills instruction on reading comprehension of junior high EFL students in Taiwan (unpublished master thesis). National Sun Yat-Sen University.

Yorio, C. A. (1971). Some sources of reading problems for foreign language learners. Language Learning, 21, 107-115.

Zarei, A. A., \& Lotfi, P. (2013). The effect of dictionary type on the recognition and recall of concrete and abstract L2 vocabulary. Roshd FLT, 27(2), 46-55.

Zarei, A. A., \& Naseri, D. (2008). The effect of monolingual, bilingual, and bilingualized dictionaries on vocabulary comprehensionand production. TELL, 2(7), 42-69.

\section{Copyrights}

Copyright for this article is retained by the author(s), with first publication rights granted to the journal.

This is an open-access article distributed under the terms and conditions of the Creative Commons Attribution license (http://creativecommons.org/licenses/by/3.0/). 